\title{
Discussion on the Model of City Spatial Structure from the Perspective of Social Choice Theory
}

\author{
Fang $\mathrm{Li}^{1, \mathrm{a}}$, Huiwu Yang ${ }^{1, \mathrm{~b}}$ \\ ${ }^{1}$ School of Civil Engineering and Architecture, Nanchang University, Nanchang,330031, China \\ a 1210156405@qq.com, b31508085@qq.com
}

\begin{abstract}
Key words: Urban spacial structure, social choice, personal preference, social ecology
Abstract. The model of urban spacial structure is a significant regulatory mechanism to control the urban space resource distribution by planners. It is the result of conflict selection by government,citizens and other economic institutions. As the reflection of public benefit, planners should utilize the social choice theory and the mechanism of urban spatial structure, in order to optimize urban spacial structure, achieving social and ecological benefits, keeping a balanced distribution of resources and Social equity, and at the same time, enhancing social justice and promoting city development.
\end{abstract}

\section{Introduction}

In 1990s and beyond, the housing market reform promoted the unit disintegration compound , which was originally organized by the housing, work and social services and other highly complex urban functional units gradually evolved into the urban level of spatial organization. Urban residents can freely choose their place of residence. Enhanced mobility, and the material space and social space structure in the city have been changed dramatically. Human geography, urban and rural planning and other disciplines have a lot of research on the urban spatial structure. In Yue min Ning, Tingwei Zhang and other scholars research[1][2] based, the main power of urban space evolution is defined as the government, city economic organizations and city residents by Song Shi[3]. According to the principle of market economy, based on the demands of different interests, they launched the game, which will ultimately affect the development direction of urban space structure.In china, the government is in a strong position, and the strategy, policy choice, investment direction often have a decisive impact on the city structure. After the reform of the housing market. According to the law of economic development and the principle of efficient use of land by local government, and actively invest a tons of money to build urban centers or new centers, hoping to promote the development of the city by strengthening growth. This model of urban development has greatly stimulated the prosperity of market economy, changed the consumption structure and housing preference, location choice and social economy connection became the important dimension of housing choice. The location choice of many enterprises, family and social subjects are intertwined, and become the city's excitement, the central area of further polarization, the rapid increase in population density, brings the double pressure of the material space environment and the social space environment.On the one hand, the urban central area traffic pressure is increases, and the home environment has deteriorated, but because of the continuous investment of government image projects, the central area of the "heat" is not reduced.On the other hand, the urban central area is often dominated by the elite and the rich, and the removal and transformation of the urban central area, the poor further marginalized, social stratification and isolation problems highlighted[4].

In recent years, scholars have paid attention to the impact of the change of urban spatial structure on the home environment,and actively explore the theory and methods of urban spatial structure, this research in addition to the explore of center's evacuation and residential differentiation, which mainly focus on the mechanism of urban spatial evolution, low carbon urban spatial structure model and other material space level, and thought realize the sustainable development of the city, spatial 
structure adjustment should coordinate employment[5]. Based on this, the concept of "low carbon" has been widely recognized, in the face of all the pressure, the city is adhering to the idea to actively promote the adjustment of urban structure, multi center construction, grading matching is its core content. However, with the economic and social transformation and the improvement of people's living standards, material level will no longer be the sole pursuit of people, social management and place spirit has become the standard of value judgment of urban residents.

\section{The Revelation of Social Choice Theory and the Thought of Urban Spatial Structure}

Kenneth Arrow (Kenneth J. Arrow) and Amartya Sen (Amartya K. Sen) are renowned for the achievement of social choice theory[6][7], who were awarded the Nobel Prize in economics in 1972 and 1998.In the famous economist Social choice theory, social development is not determined by the forces of a substance, but the process of people's unconscious choice. There is a potential demand pattern from low level to high level in the human choices, in this process, human beings choose to meet the low level's need first, and then select to meet the need of a slightly higher level. In the lower level of basic survival stage, people choose the material conditions of its production needs first, so the economy is in the status of the decision. With the development of society, however, now that human spirit has become the leading force in the development of society, people choose the economic and social management not only from an economic point of view, but more from a cultural perspective, which means that society is entering into the stage of multidimensional selection. China has always stressed the importance of achieving personal values in the collective interests, which is a great contrast to the West's emphasis on the culture and ideology of individual supremacy, therefore, there is a big difference between China's urban social choice in personal preference and the West. Since the founding of China, welfare housing system has been existed for several decades in China, due to the indifference of housing and its distribution system,personal preference is almost not reflected; after the 1980s, China began to reform the housing system, physical distribution gradually over the monetary distribution, enterprise-effective workers can obtain better houses, the polarization between the rich and the poor began to exist in urban residential space. Not until the commercialization of housing reform, people didn't choose their own "ideal home"for a positively or negatively way based on their own circumstances, a mixed residential communities started to become the city's "cell". With the deepening of reform and the development of market economy, whether the patterns of settlements led by unit compound in the past or committing to the pursuit off linty environment of Residential Areas, requirements of urban residents can't be met, People's eyes began to turn to social management and cultural environment, society is becoming increasingly diverse needs of the stage, the definition of the working people and of life itself is also the beginning of a big change. Government decision-making under the guidance of the traditional economic model and social choice approach derived from it has been difficult to adapt to new developments, based on humanism and the human spirit, the diverse needs of society for people gradually get attention, social decision-making began to absorb the views of the wider community. The rapid development of virtual community demonstrates the lack of real community building, Characteristic community construction is imminent, whose essential requirement is diverse, healthy and alternative residential environment.

When the theory of social choice analyzed whether social choices adapt to people's needs or not, it emphasized that social choice should respect individual preferences, and arranged different social status's order in justice, in order to achieve the purpose that social policy-making can meet the maximization of social welfare. Currently, the society is undergoing a drastic transformation period, Interests of the main body of diversification and personal interests of the main consciousness will continue to be enhanced unceasingly, personal preferences and social choice conflict is inevitable[8], what we want to study is how to establish an effective social choice's rules to 
reconcile this conflict, thus forming effective social decision-making, and promote social equity and achieve social recognition.

The values of "Living Space justice"[9] believe that the justice of the production and the space allocation of residential space is a fundamental right and obligation of citizens. However, market mechanism has caused the purchase power to become the important standard of space consumption.e, resulting in a phenomenon of living space injustice. The market can not provide equal opportunities for people to choose, the price criterion is the basis of the market, and the current price's difference lies on the enjoyment of public resources. Based on this, the mode of urban spatial structure should be based on the achievement of public resources enjoyed by indifference into a starting point to ensure that people's personal preference is no longer are repressed for those issues like housing prices, they can choose their own identity "ideal home"based on their own communities, this option is active voluntary rather than negative forced, which is the meeting point of urban social choice and individual preferences, but also the urban structure essential requirements of ecological space. Therefore "harmonious society" and "China Dream" can be achieved.

\section{The Coupling Relationship between the Evolution Mechanism of Urban Spatial Structure Model and Social Choice}

As it was said in the New Marxism theory, Configuration and the formation of the spatial structure of urban space resources, which are reflecting the levels of all urban classes, and the formation of social relationships in physical space. In the past 3 decades, the government stimulate the economy by reforming, with ignoring the social equity, which stimulate stratum differentiation.The economical function of the government determines its become the representative of the wealthy, who have taken up dominant position in the city,however, those vulnerable groups have been marginalized. Out of political considerations, the government will continue to invest to dominant districts, hoping to improve the transportation, build public services and infrastructure. In accordance with the principles of market economy, social investment will also be attracted to the dominant districts, so the urban space will be further polarization, aggravating the formation of the poor district and the rich district. Zhiqiang Ren said, it's normal to divide Chinese housing into the rich and the poor. Since Beijing has featured with"east rich west wealthy south poor", and the sharing degree of public resources has naturally distinguished the rich and the poor. The coexistence of Urban material space polarization and social space polarization made the society unstable, and produced some extreme psychology and behavior, such like resenting the rich and the officials.

The government has strengthened the construction of the political housing, with aims to improve the social harmony. To a certain extent,it relieve the social ecological environment deterioration.

However, basing on the theory of "growth pole", the rapid developing China city adopt the "stronghold" development mode, and the layout of the city always shown as attachment of production space. Every industry development and transformation make resources reconfigured in urban society. The demand was always exceeding the supply which makes those social elite have occupied perfect location with good geographical advantage, complete facilities, The government's "image projects contribute to rising central city house prices further, forming a vicious circle, which high-income people's come in, low-income groups forced to choose to leave to form the central "eliminate ten thousand yuan housing" market logic. The research of scholars and government decision-making sometimes accepted the phenomenon, and indulgent the development of this kind of behavior. In 2005, the Beijing land and resources Bureau, has said, the economical housing projects will be limited within the east, west, north fourth ring road and south third ring road and its extension bordered with fourth ring road. In Shanghai's real estate development, some scholars even put forward that people living in the inner ring speak English, speak mandarin between inner ring 
and outer ring, and speak Shanghai dialect outside the outer ring. Capital appreciation are achieved by resources taken. Without good education, health and other public resources, middle-income class fall into a trap, and it is hard to come out from poverty. The maximum fair expected by social choice has not been achieved, and a series of social negative effects occurs, which increase distance between people. What lacking of security, cause class antagonism and office resentment. The justice social system should help the adverse, increase their opportunities and hope, reducing the gap between them and the rest of the population through a variety of institutional arrangement[12]. Based on this, the city government has chosen the multi-center model of urban spatial structure, considered it would relieve the pressure of the population of the old city and was the effective ways to realize green low carbon city. The urban district grow fast and new city center quickly occupied. Since fixed investment and government sloganeering propaganda improve people's expectations, house prices come to the virtual height. Under the condition of the acceleration of urbanization and population, the new poles and fringe area begin to form. In the process of rising house prices, the country issued a series of housing market regulation policy since 2003, to inhibit people's investment preferences, but its effect is not obvious. On the one hand, we should respect individual preference, meet the needs of people's living and investment; On the other hand, we want to avoid excessive polarization of social space. This looks quite contradictory, and polarization of urban space has formed in the people's unconscious choice.

Migration theory also interprets how social choice influence urban spatial structure. Due to more opportunities and more public resources, the city and central area are more attractive, comparing to the village or fringe area, Therefore, rural-urban migration, fringe-center migration, the Midwest city - central or coastal cities migration and even developing countries - developed countries migration is inevitable.Excessive migration, however, is the root causing the polarization.It brings huge social costs, such as urban-rural gap is widening, native of the city further polarization, contradiction between native and foreign to further expand (part of the people in Hong Kong slander mainland bring the "locusts" because their large migration). Migration is not inevitable, because familiar natural and humanistic environment, strong social identity are migration resistance. It is necessary to formulate relative balance of living environment on the system, to enlarge the resistance to eliminate social injustice, and to realize the happiness of people, achieving the goal of retain potential migrants. The referred sociology about social choice how influence on urban spatial structure evolution has two theories each involve the personal preference and social choice conflicts.

According to the views of dialectics, contradiction in itself is the unity of opposites. Social choice has to respect personal preferences, and personal preference has to conform to the social expectations. It's necessary to restructure urban spatial structure, to establish equality, justice, material resources and social resources sharing rules.

\section{Optimization of Urban Spatial Structure in Social Choice Theory}

To achieve social choice people should respect individual preferences, create a diverse, healthy, and free environment of urban communities, as well as necessary reconstruction of the urban space. Organic evacuation theory put forward a vision about high dense urban evacuated into a plurality of central and low-carbon urban spatial structure also uphold this point of view. This guideline a direction of action for solving the problem that the excessive accumulation of public resources lead to disparity housing prices on the city center and outlying areas. Cities and regions in many countries on the world are actively studied and implemented a multi-central development model, such as Tokyo, London, Paris, Moscow, and so on. Polycentric mode provide more opportunities to choose by dispersing of public resources and urban space. So people do not have near the city center and will be able to more easily access to modern life of public amenities. This bright more the benefits of the general public, and greatly reduce costs of transportation and time. Polycentric urban 
structure has been recognized by the world, and our country has also been done a lot of practice, but the actual effect is still not as expected. The main reason is the government played a "disgraceful" role. Firstly, in the new area development aspect, the government need to considerations their achievements and obtain required development funds, so they invest a lot of infrastructure in the new district center, sell a large number land, and actively decrease profit. As the force of administrative intervention has always been extremely strong in economic development, it rapidly push up the people's expectations, and house prices rose sharply to artificially high position as well as land prices. But everything is appearance, "ghost town" is its essence. This is because of any without historical accumulation of urban development is difficult to resist financial risks. In addition, in aspect of the multi-center development model required to establish a hierarchical support facilities, the government functions often absent, and they only care about the new district center as well as will focus on invest it, then the central area is natural to quickly become a "the darling", while the other center is often overlooked, so the unfair of economic development is inevitable. Government should focus tends to be more balanced with taking into account the surrounding area, especially lots of unfavorable locations, the rapid development of the central area need to depend on the support of the surrounding prosperity area. Balanced investment is not negate agglomeration effects, and blindly centralized or decentralized cannot guarantee the sustainable development of cities. The combination of centralized and decentralized can effectively play the advantages of both.

In the situation of relatively limited funds, government give inadequate investment in infrastructure to non-priority areas, which is an important reason for the existence of differences in the city center area and the edge area. In these years of market economic development, the government is only concerned about the development of key areas, and eager to get rid of the "burden" from other regions facilities that will be solved by the market. But the power shortage of the market itself, leading edge region lagging behind, and become a vicious cycle. For example, "luxury office buildings get together in Henan, but schools and dormitories as refugee camps." In our specific social environment, the government is the ultimate monopoly of resources, so they must assume the task of construction community facilities, and that this construction must be no difference in areas. Admittedly this is a huge project. In order to make the government get the courage to take on this responsibility, it is necessary to be clear in the statute, and established a number of criteria. One problem is that the performance evaluation of government has always been a larger defects, they focus on GDP and the appearance of prosperity. And priority to efficiency in the market economy as well as long-term lack of attention to equity issues, result in unsustainable social development. To make governments put energy into construction of facilities, rather than perfunctory, there need to have a more comprehensive evaluation mechanism as a support, and such an evaluation mechanism will be an important aspect of the current political reform.

Urban spatial structure of multi-center and graded perfect facilities is the skeleton network system of the city, and meet the requirements of the people for the substances. And community spirit on the city, and social identity is the flesh and blood of the city. It is the needs of urban people's spiritual life, and urban communities is its carrier. World Health Organization will community defined as: "social groups within a fixed geographical area, and its members have a common interest, recognize each other, the implementation of social functions and create social norms, to forming a unique value system and social welfare. Each member was through the family, neighbors, community and integrate into the larger community". Some scholars get a conclusion that features of formed community are in four aspects, including the people, geography, social interaction and social identity. Thus, the community is no longer a simple "residential area" concept, it is feelings. To nurture such feelings and get social recognition, people need to generate lasting social ties in social interaction, and ultimately the formation of community culture, so that people living in this area and be able to feel the status of ownership, and therefore feeling pride. People choose the "ideal home" under emotional rather than prices, so "personal preference" and "social choice" integrate in this, and a better vision of living space planning can be achieved. In the community, the position of 
community organizations is not to be underestimated. In Hangzhou in China, the government gives the community the definition of the seven basic functions that respectively is management and coordination, community service, community policing, health care, environmental maintenance, educational and sports, and social security. Community organizations are no longer just management functions, and it increasingly serves as service role acting as a bridge role in social interaction and this role is indispensable. Planning of urban spatial structure will also no longer simply a planning of substance spatial structure, it also includes planning of social spatial structure. And such planning is not reply on the economy itself, it will a multi-center, homogeneous, and have their own characteristics functional space unit[13].

\section{Conclusions}

"City to make life better". A better urban life depends on people efforts. People change its position and level in the ecosystem of social and to realize its value. Based on their personal preference, equality and the freedom to choose their own "ideal place". Given the urban spatial structure have social choice mechanism and its role is important in the regulation of urban resources, the government and planners should burden the necessary responsibilities, abandoning the focus on efficiency,pursuing the concept of economic efficiency. They should also adhere to the concept of the structure of ecological spatial, and try to create a non-exclusive urban spatial structure mode, so that people can enjoy equal access to public resources, and create a harmonious and sustainable social environment.

\section{References}

[1] Yueming Ning: Acta Geography Sinica, Vol.53 (1998), p. 470- 477.

[2] Tingwei Zhang: City Planning Review, Vol.25 (2001), p. 7- 14.

[3] Song Shi: Urban Planning Forum (1) (1998), p. 50- 52.

[4] Huiwu Yang: Applied Mechanics and Materials, v 99-100 (2011), p 457-461.

[5] Haixiao Pan, Xi Tang, Jinyu Wu, Yuan Lu, Yangfei Zhang: Urban Planning Forum (6) (2008), p. $57-64$.

[6] Kenneth J. Arrow. Social Choice and Individual Value. (Ding Jianfeng, Shanghai: Shanghai People's Publishing House, 2010).

[7] Amartya K. Sen. Amartya. Collective Choice and Social Welfare. (Dede Hu, Yuda Hu, Shanghai: Shanghai science and Technology Press, 2004).

[8] Henglong Zhang, Xian Chen: Journal of Zhe jiang University(Humanities and Social Sciences), Vol.36 (2006), p. 80- 87.

[9] Shuwen He, Jun Zou: International Urban Planning, Vol.25 (2010), p. 31 - 35.

[10] Guoen Wang: The social choice theory of urban planning(Shanghai. Tongji University, 2005)

[11] Weixuan Song, Qiyan Wu: Chin. Geogra. Sci.Vol.20 (2010), p 568-576.

[12] Hongling Qin: Modern urban research, (9) (2006), p 81-84.

[13] Guangrong Wang: Journal of Tianjin Normal University (Social Science), (4) (2006), 23-27. 